\title{
Heads in the Sand
}

$\mathrm{R}$ ome has been sacked. The pyramids are crumbling. The locusts are swarming. Okay, maybe things are not quite that bad. But for all of you non-U.S. readers, please forgive some all-America self flagellation. Because of the nature of journal publishing, I am writing this editorial in late May, after just returning from the United Nations World Conference on Biological Diversity, held in Bonn, Germany. You are reading this in late August or September, as the campaign for U.S. president is cranking up to the moment of truth.

While there were literally dozens of events held at the World Conference on Biological Diversity, the two focal activities were the 9th Conference of the Parties (COP) to the Convention on Biological Diversity (CBD) and the 4th Meeting of the Parties to the Cartagena Protocol on Biosafety (COP-MOP 4). I was in Germany as head of delegation (of one) for the Society for Ecological Restoration International (SERI), which was for the first time granted observer status at the COP to the CBD. My main purpose was to meet with the Executive Secretary of the CBD, to see how we could elevate the role of SERI and ecological restoration in the CBD process.

Sadly, out of the entire world the only major countries who are not signers of the Convention are the U.S., Iraq, and Somalia; the only other nonsigner states are Andorra and the Holy See. In preparing me for the meeting, SERI Project Director Sasha Alexander remarked to me, ". . . and Iraq and Somalia don't even have functioning governments." My retort was ". . . and are you trying to tell me that the U.S. does?" And let's not even dream about the U.S. being a signer of the Cartagena Protocol on Biosafety.

During the last eight, very long, years, the United States of America has become an international pariah, falling to a level so low that I often find it embarrassing, as a representative of U.S. interest in biodiversity and ecological restoration, to travel and work in the international arena. The whole world realizes that human-induced climate change is upon us, that sea levels will rise with catastrophic consequences, and that the accelerating loss of biological diversity will have serious implications not just for aesthetics and ethics, but for human livelihoods. The U.S.

Ecological Restoration Vol. 26, No. 3, 2008

ISSN 1522-4740 E-ISSN 1543-4079

○2008 by the Board of Regents of the University of Wisconsin System. government, not wanting to be constrained by international law or treaty, has distanced itself from the international community concerned about climate change and biodiversity. We are Rome. And we are burning.

In his 2006 book, Plan B 2.0 Rescuing a Planet Under Stress and a Civilization in Trouble, Lester Brown, founder of the Worldwatch Institute (among many other accomplishments), estimated that it would cost 93 billion dollars per year for an Earth Restoration Budget. This budget would include reforestation, topsoil protection on croplands, rangeland restoration, fisheries restoration, the protection of biological diversity (the costliest single item at $\$ 31$ billion), and the stabilization of falling water tables. Meanwhile, the U.S. is spending $\$ 100$ billion per year or more on wars in Iraq and Afghanistan. Where did we go so wrong? When did the formerly fiscally conservative Republicans start spending money like it grew on trees? And why is it so much more appealing to Americans to blow things up than to fix them, heal them, and restore them?

This brings me to the carbon wars. The magazine Conservation recently published an article titled "Do Trees Grow on Money?" in which author Pearce discusses the efforts to commercialize carbon credits in line with the Kyoto Protocol (of which again, the U.S. is not a signer), by reducing carbon outputs from deforestation, especially in the tropics. The article states that these efforts could backfire, actually accelerating deforestation in the short term and pushing indigenous peoples from their homelands. In my mind, it is imperative that we, as restorationists, intervene in the carbon process and the sooner the better. It is true that not all restoration activities are carbon positive, but most are, and even those that normally release carbon (such as reintroducing fire to fire-suppressed ecosystems) could be retooled to reduce or eliminate carbon outputs. In particular, the protection and restoration of peatlands is gaining traction in the international community as a way of sequestering carbon. So crank up those grant proposals.

COP 9 in Bonn drew 7,000 people. Around the same time, an oil and gas energy conference in Houston drew 70,000 , so as well as we are doing in greening the planet, the industrial realities are that we are still way behind the curve. At COP 9, SER also released its first Briefing Note, on the necessity of cooperation between conservationists and restorationists in order to achieve our mutual goals (www.ser.org/pdf/SER_Briefing_Note_May_2008.pdf). The CBD has a target of reducing the rate of biodiversity 
loss by 2010, which is widely regarded now as impossible (note that this is the rate; extinctions will still occur, just more slowly). Other major concerns are ocean fertilization (which at least one company has had the audacity to say was restoration, in the media), genetically modified organisms, biofuels production (another area where the ecological restoration community had better get involved quickly), marine protected areas (which is rapidly gaining international support), bioprospecting (biopiracy to some), and the rights of indigenous peoples and local communities, especially in protected areas.

I know that many readers of Ecological Restoration work at the local level and may not be particularly focused on international issues. I plead with you now to look around at the national and international situation, to get involved in the political process, and to encourage our elected officials to reengage in the international community. We need all of you with experience in restoration to make your voices heard. I do not know what will happen with the 2008 elections in the U.S., but I can hope that something extraordinary and positive will break us out of the pit we are in and allow us to pull our collective heads out of the sand.

George Gann

Chair, Society for Ecological Restoration International 